\title{
Factors Affecting The Use Of Information Communication Technology In Teaching And Learning In Saudi Arabia Universities
}

\author{
Edrees A. Alkinani ${ }^{*}$ \\ Computer Science Department, College of Computing in Al-Qunfudhah, Umm Al-Qura University, Saudi \\ Arabia.Eakinani@uqu.edu.sa
}

\begin{abstract}
Technology and machine learning are becoming increasingly important in Saudi Arabia educational system. There is a growing demand for educational institutions to use machine learning to teach the skills and knowledge students need for the digital age towards Saudi Vision 2030. The integration and adoption ofdigital technologies into learning and teaching brings more opportunities for Saudi universities students and teachers to better embrace the globalized digital age. There is huge potential for the Saudi educational system to perceive the key role of digital technologies inenhancing the education process quality. The aim of this article is investigating the barriersthat affectteachers' integration and adoptionof information communication technologies(ICT) in universityclassroom. The study adopted a qualitative research design to collect the data through the semi-structured interview. The sample of the study is four Saudi ICT-experts professors from four public universities in Saudi Arabia. The findings of the study showed that there are three types of barriers namely; teachers' level barriers e.g. attitudes, knowledge, access, resistance to change. Technology level barriers e.g. compatibility, perceived of useful, institutional barriers. Institutional level e.g. leadership support, resources. The recommendation and suggestion for studies were suggested in light of the findings.
\end{abstract}

Keywords:

E-learning; ICT; technology integration; Saudi Vision 2030; technology-based learning; Saudi Universities; Saudi Arabia.

Article Received: 18 October 2020, Revised: 3 November 2020, Accepted: 24 December 2020

\section{Introduction}

Related past studies have demonstrated the relevance of incorporating advanced technologies to boost Saudi universities' education (Alkahtani, 2017). Such findings show that ICT devices are either less accessible or that the devices are insufficient to teachers for everyday activities, such as the need to show graphics through technical means to students(Al Mulhim, 2014; Alakrash et al 2020a). The reports on exposure to ICT facility in various Saudi Arabia sections were substandard (Albugami, 2015, Ageel, 2011). Like "renting rooms," which are not intended to act as classrooms, some colleges are improperly designed to provide ICT equipment. Many concerns are surrounding the introduction of ICT services into university programmes, particularly the obligation to include proper instruction for teachers in particular before the curriculum begins and ongoingly, as needed (Robertson \& Al-Zahrani, 2012). The teaching shall concentrate in respect of contents and implementation strategies on ICT facilities functioning and the programme(Oyaid, 2009). The ICT system is also concerned. Initially, they have to be accessible and secondly; they have to be structurally efficient. In favour of both instructors and learners, quick entrance to peer guidance in infrastructure repair is important(AlAsmari\& Khan, 2014, Alakrash et al., 2020b). ICT facilities that perform properly and is properly managed would allow a change from the teaching exchange paradigm (teachers distribute knowledge but there is typically no additional conversation or debate) to a "questioning method" approach(Almalki\& Williams, 2012). ICT problems will not be overcome by default; however, it should assist both the questioning model and the transmitting model, i.e. ICT 
accessibility and service on its own does not consist of the single discrepancy (Al-Maini, 2013, Razak et al., 2018).

\section{Incorporation of ICT Equipment in Teaching in Saudi Universities}

In Saudi Arabia, as well as several different nations, the academic transition taking place today is motivated by rivalry in productivity expansion. Usually, it entails the introduction of technological advances as a kit, coupled with instructional practices that foster critical thought and innovation. That is partial since the centre of the current programme is an academic study, and learners utilise the network to do the study(AlMadani\&Allafiajiy 2014). It has not been possible for educational institutions to provide libraries wherein the learners can search for information in infinitely diverse regions that just newly acquired comprehensive education and Saudi Arabia. Instead, governments sometimes tend to push learners to the website to study most commonly utilised in current public and industry performance instead of buying those libraries (Al-Maliki, 2013).

Despite extensive evidence of the advantages of technology in the transformation of educating and critical thought, it is also noted that many of teachers, particularly at university standard, are not enjoying the privileges of network technologies to modify their pedagogy techniques (Alhawiti, 2013, Alakrash\& Razak, 2019). Teachers in several areas around the world were shown to be increasingly inclined to follow ICTs to prepare classroom worksheets, schedule classes, maintain notes and submit emails (that are also both roles which increase teachers performance) rather than position technology in possession of learners to perform individual study and classroom demonstrations (Alkahtani,2016). Part of it could be attributed to challenges faced by teachers in moving to modern instructional techniques that involve technology use. Software usage is more successful in a collective training and educating society and aims to change the equilibrium of authority and experience among instructors and the learners, innovations that would not all be pleasant (Alzahrani, 2017, Alakrash\& Razak, 2020a).

Nevertheless, several reports have shown that impede machine implementation's key reasons are not entrenched behaviours and perceptions (Alkahtani, 2016; Al-Madani\&Allafiajiy, 2014, Alakrash \& Razak, 2020b). Instead, the lack of three realistic organisational strategy techniques is a major element.

- An approach of creating accessible PCs, topnotch instructive programming, and computerised devices, for example, those interactive display's tools, totally in a decent state, and educational institutions' organising of classrooms and access to make PC utilise promptly attainable. Past research by and large concur that accessibility of the required facilities is needed to access PCs in educational programmes effectively and is likewise a significant cause behind why the enactment is regularly not favourable. PCs and other technologies used for educational purposes are costly and inclined to fail if not appropriately managed.

- Accessibility of satisfactory ICT preparing for teachers before they start to utilise PCs in their teaching, and proceeding after that as required. Making PCs accessible to all teachers provides them occasions to discover PC aptitudes by experimentation or from online exercises and urges them to utilise PCs for their expert and individual necessities. Institution approaches that empower casual assistance and cooperation in PC use among teachers likewise extend information and raise trust in utilising PCs. Particularly among teachers who are foreign to technology use, the participation needed to design ICT-based exercises for classroom use might be more prominent than the time expected to design exercises without it, and consequently, 
universities ought to change their timetables to give instructors additional time (Asiri, 2012).

- The level of consolation and assistance from the head of the institution and the rest of the colleagues who rise to guide in attempting to encourage the degrees of ICT adoption and excitement. Past perspectives might impact teachers" mentalities toward PC use; by ideas of demonstrable skill; by the perspectives of the head, the rest of teachers and guardians; and the institution and general scheme (Albugami\& Ahmed; 2015).

These variables were referred to as challenges following studies on ICT performance in Saudi universities before the King Abdullah Project for the Development of Public Education. Past research by Alharbi \&Lally (2017) and Asiri (2012)arrangement and performances in institutions in various divisions of Saudi Arabia toward the start of the new golden age. They discovered that a few institutions were ineffectively prepared to convey ICT, not limited since some struggled in "leased homes" (for example, in constructions that were not constituted to fill in as establishments for classes). Similarly, significant were deficiencies in PC experiences. The two investigations accentuated the substantial remaining burdens of instructors. They attempted to coordinate PCs into the educational plan, and the helpless preparing open doors for teachers to build up the important ICT abilities. The ICT preparation programmes were depicted as excessively theoretical and as zeroed in on PC programming, as opposed to creating fundamental PC education aptitudes, which would have helped students and staff use PCs as data references and work devices (Almaghlouth, 2008).

Addressing in the paper Almalki\& Williams (2012) detailed that there was yet an over the top dependence on the utilisation of customary schooling strategies in the King Abdullah Project schools, regardless of the way that advanced techniques could be more proficient, lessen the pressure on teachers and enhance understudy scholastic execution. He proceeded to note that, "Today, teachers are encouraged to integrate technology into their personal and professional performance to complement the subject matter and to facilitate the teaching process." Abdulghani (2014) states, the information blast has demanded teachers to build their instructing and training's viability and productivity, achieving deeper knowledge in a more limited extent, which has been achieved using ICT. Teachers have discovered a lot to recognise ICT as an instructive device. To start with, it is an amazing wellspring of data for experimentation and universities tasks. Next, modern innovation offers the methods for relational correspondence to widen teachers" expertise through an intelligent coordinated effort with others throughout the world.

\section{E-learning in Saudi Arabia Universities}

The public authority of Saudi Arabia has delivered the reconciliation of E-learning devices in instructing and schooling as a need(Aldiab et al; 2017). Certainly, this plan is found in the 'Saudi vision 2030' programme. One of the principal objectives is to guarantee that, later on, five Universities in Saudi Arabia are among the main 200 Higher Education establishments around the world. Throughout history, the Saudi administration has attempted to develop its schooling cycle by apportioning assets and assets to expand its worldwide reputation and adequacy. As a feature of its progressing attempt, the Saudi Ministry of Education set up the National Center of E-learning and distance education in 2007 (Ministry of Education, 2017). The National Center for Elearning and Distance Education grants a few specific preparing programs in E-learning and distance training. These projects have been grown occasionally with the assistance of both Saudi and global specialists in the E-learning field. One point of this programme is to help Saudi colleges to present ICT in their instructive setting and guarantee that E-learning systems and stages are 
coordinated and received by understudies and instructors inside the Saudi training framework (Ministry of Education, 2017). Moreover, the programme aspires to advance coordinated efforts among Saudi colleges to prepare and assist with the goal that teachers can utilise ICT instructive arrangements in their tutoring and educational programs (Tayan, 2017).

A few foundations are, as of now, working together with the programme to coordinate ICTbased educating and learning measures into their usual methodology. One illustration of this is the Princess Noura University, which has served with the programme to plan and create E-courses and preparing programmes for employees. Alternately, different colleges have been more independent and have tried to present and execute their E-learning subjects and arrangements into their particular educational programmes by developing their administrator of E-learning. This administrator is accountable for planning and delivering these Econtent plans, just as preparing scholastics and understudies to utilise and receive the new frameworks and urge instructors to utilise Elearning devices in their schooling pedagogy. Situations of Saudi Universities adopting this strategy incorporate Hail University, Al-Jouf University, King Abdoul Aziz University, Umm AlQura University, King Khalid University, and AlTaif University.

\section{The objective of the study}

1. What are the potential obstructions that restrict teachers' and students' genuine utilisation of modern technological advances in education?

\section{Methodology}

The investigation appears as exploratory and elucidating research, concentrating on the components that impact teachers' provision and mix of ICT in educating and learning. To accomplish the investigation goals, semi-organised meetings were led with four teachers concerning their points of view on the reception and coordination of ICT into instructing and learning. The examination utilised a qualitative methodology to give an inside and out portrayal, conceptualised inside the hypothesis of practical hypothesis strategy to clarify the components that impact or obstruct reception and combination in educating and learning measure. Six teachers were drawn closer to take an interest in the investigation; four out of six instructors consented to partake in the research.

These four lecturers came from two Saudi universities. They were proposed open-finished inquiries. The meeting gave a top to bottom comprehension of the fundamental concerns' imperative to the research, for example, the elements that impact or limit teachers' choice to receive and coordinate ICT in teaching and learning. Questions are flexible, and a generally disorganised discussion design was selected. The cycle of information examination in the qualitative study "includes running with information, arranging them, separating them, incorporating them, looking for designs, finding what is significant and what is to be realised, and choosing what the results you will show". All through information assortment, information examination will happen through methodical strategies concerning deliberation and correlation laid out in the practical hypothesis strategy.

\section{Findings}

The information outline measure included distinguishing styles in the information. These styles included concerns proposed more than once beyond interviews, normally observed in ICT utilisation in educating and learning exercises or sentiments, which kept re-showing up. The information was dissected inside each case just as across the cases to distinguish relationships and analyse contrasts. The underlying ideas that arose in one event setting were then differentiated, explained, and fitted in the other. Inside the 
principal event, the repetitive methodology of information assortment, data coding, and study was more unrestricted and generative, zeroing in on the improvement of ideas, attributes, and associations, and grasping the depictions of the way to produce a practical hypothesis.

The complete review of the events and all the information presented from the meetings and evidence were inspected and encrypted by concentrating on the elements that impact or block choice and incorporation of ICT in instructing and learning. It is perceived as open coding and it depends on an insightful procedure of recognising potential classes and the characteristics and depth. When all the information was analysed, the ideas were coordinated by the repeated subject. Those topics displayed a prime possibility for many steady and regular ideas, which connected various related thoughts. It is identified as axial coding and depends on a manufactured strategy of making associations between subsets to develop a complete plan. The case information was then reconsidered and recoded utilising this proposed structure; the objective is to decide collections of classifications and ideas that met as much of the information as could be expected.

This repetitive assessment yielded a bunch of general classifications and related ideas that portrayed the notable limitations, occasions, and encounters related to appropriation and coordination of ICT in the first teachers' situation. These underlying ideas led to the leftover teachers' situation, permitting the cycle of information assortment, data coding, and examination to be further focused on. Subsequent to the consistent similar investigation strategy (Glaser and Strauss, 1967), the underlying teachers' cases conflicts were methodically looked into with the subsequent teachers' case. The study likewise utilised Miles and Huberman's (1984, 1994) method for acrosssite design examination and collecting, including matrix showcases to look at pivotal occasions, prompt, and results. The outcomes demonstrated a beneficial connection between teachers-level, innovative and institutional components and less for obstructions to ICT selection and reconciliation (protection from replacement, absence of preparation, absence of access, and absence of specialised help). Throughout all these cases, teachers-level mechanical and institutional variables (assets) were harmonious with the appropriation and reconciliation choice, aside from one instructor that did not demonstrate a yes for assets.

Information from the subsequent instructor case was initially arranged into the first teachers'" information's underlying ideas. It before long turned out to be clear notwithstanding, that the underlying ideas produced by the initial teachers' case did not oblige a portion of the discoveries arising out of the subsequent teachers' case. Obliging the subsequent teachers' cases encounters prompted some significant elaborations and explanations in the arising hypothetical system and constrained a reexamination of a portion of the primary teachers' case's encounters. The way toward looking into the teachers' case information was rehashed for the rest of the teachers' cases. Revising the underlying ideas to fuse contemplations of the subsequent teachers' case's encounters required getting back to the primary teachers' case information and rearranging and re-examining them to assess the more extravagant ideas and more intricate relations presently establishing the structure.

The capability to fuse extraordinary experiences throughout the examination is one of the advantages of a practical hypothesis technique, an illustration of something Eisenhardt (1989) names "controlled opportunism," where "specialists exploit the uniqueness of a particular case and the rise of latest subjects to develop outcome theory" (Eisenhardt, 1989). The cycle among information and ideas finished when adequate classifications and related ideas were characterised to clarify what had been seen in all the teachers' cases. No extra information was discovered to create or continue to arrange ideas and classifications, a circumstance 
alludes to as "theoretical saturation." The consequence system is experimentally legitimate as it can represent the exceptional information of every teachers' case, just as sum up examples across all the teachers' cases (Eisenhardt, 1989).

Triangulation over data collection strategies (interviews and evidence audit) is then attended to fortify the arising ideas. The consistent relative technique likewise needs the looking out and checking differences and negative proof, subsequently constraining the showdown of arising clarifications with conceivable electives. Lastly, holding in-depth interview records from every teachers' case, the sections produced gave the foundation to build a subjectively valuable account depiction of the enactment and incorporation of ICT in educating and learning. The record was then taken back to the participating teachers, who gave critique, rectification, and comment on the results and analytical model outlines.

\section{Discussion of the result}

The contextual analysis outcomes were utilised to build up a hypothetical model for objectifying the hierarchical concerns encompassing the enactment and synthesis of ICT - problems that have been to a great extent blowing from concurrent conversations of ICT utilisation (Al Gamdi\&Samarji 2016). The consequences of the various contextual investigations will be examined regarding the classifications that arose out of the indoctrinated hypothesis study measure. The goal is to distinguish and offer essence to every one of the classifications.

\section{Barriers to ICT adoption and integration}

Obstructions to ICT allocation and incorporation are deterrent, forestalling or restraining teachers from embracing and coordinating ICT into educating and learning practices. The boundaries that rose up out of the contextual investigation examination comprised an extensive scope of issues. These hindrances are placed into two collections of teachers-level boundaries and institutional-level boundaries. The teacher level boundaries incorporate the absence of teachers' ICT experience, absence of time, protection from change and unpredictability of coordinating ICT. While the institutional-level hindrances incorporate restriction of foundation, absence of preparation, absence of access and absence of specialised help are examined underneath.

\section{Lack of ICT knowledge}

ICT information relates to teachers' capacity to utilise the broad assortment of innovation-related instruments and the utilisation to institutional education, specifically, and to the entirety of educating and learning measure is vague. While the absence of ICT information alludes to the absence of widespread information and comprehension of ICT, it is viewed as a critical hindrance to the reception and utilisation of ICT in instructing and learning. The case research results unmistakably demonstrate that ICT information and expertise encourage ICT application. It is pivotal in affecting teachers' choice to embrace and coordinate ICT in educating and learning. The case outcome underpins past similar research (Quadri et al., 2017). which noticed the absence of information and abilities as components that contrarily influence ICT implementation by teachers in schooling. (AlAdwan\&Smedley, 2012, Razak et al., 2018b) distinguished elements that keep teachers from ICT use as the absence of teachers' ICT abilities; absence of certainty and absence of educational preparation.

\section{Lack of time}

Absence of time to partake in expert elevation programmes is perhaps the main parts that keep teachers from utilising PCs and coordinating ICTbased element in their classes. The teachers sensed that they needed more opportunities to utilise PCs in their classes with their routinely booked classes. The absence of time needed to coordinate ICT into the educational plan effectively is a repetitive test. The case outcome upholds what different precise 
research, Al-Shammari, \& Higgins, 2015) discovered that absence of time is the significant and vital obstruction to improve in the institution setting and incorporating ICT into the institution and educating/learning measure. As indicated by Al-Nefaie (2015), the absence of time is an element that blocks technology incorporation in school.

\section{Refusal to change}

Assurance from any changes has been referred to in past studies Alahmari\&Kyei-Blankson, 2016) studies as obstruction preventing ICT adoption and incorporation into educating systems. Teachers' mind and their characteristic unwillingness to transform from the old-fashioned method of doing things is a snag to ICT integration. At a more extensive measure, Alghathani (2017) found that protection from any changes is a significant boundary to teachers' utilisation of teaching innovations. The case outcomes reveal that a few teachers did not want to transform from the traditional method of getting jobs done. Rather the greater part of the teachers claimed that the way toward acquiring modern innovation and incorporating it in teaching requires some investment. In contrast, others feel that these may supplant them, so instead of losing their positions and old teaching technique, they decided not to utilise these modern technologies in their teaching methods.

As per one of the teacher 2, who expressed that most teachers continue providing superfluous reasons for not utilising innovations in their classrooms, for example, they are not getting enough specialised preparing.

Villalba et al (2017) discovered that, in spite of the fact that teachers felt that there was a very sizable amount of innovation accessible, they would not accept that they were being upheld, managed, or would get honoured in the incorporation of innovation into their classes. Teachers who are not utilising new innovation, for example, PCs in their teaching believe that the utilisation of ICT has no advantages or hazy profits. Lawrence \& Tar (2018) asserted that one important aspect of instructors' mentalities towards utilising advanced technologies in their teaching is how these innovations will profit their educating process and their students' understanding. Gilakjani (2017) mentioned that incorporating the new innovations into instructive environments requires a shift of mentality and various teachers will deal with this shift in an unexpected way. As per the study, teachers' reaction to change is significant in light of the fact that teachers' views impact what they do in class settings.

\section{Lack of infrastructures}

The case outcome reveals that one of the teachers expressed some worry with respect to the innovation. The teachers proclaimed specialised issues, generally identified with the constraint of ICT base, as a boundary upsetting the full misuse of ICT in educating and learning. He states that the most troublesome issue in utilising PC in education is the absence of power supply; in a growing nation like Saudi Arabia, the power outage is very normal and PC embellishments, for example, projectors will break away because of the regular power blackout. Internet connection is another cumbersome issue, the connectivity is not steady and extremely moderate, and more often than not, there is no connection at all.

The impediments of the innovations were perceived by different teachers, in spite of the fact that they had not encountered the issues individually. The teachers that experienced specialised issues held greatly about the matter. Teachers stated that it is occasionally disappointing due to the gradualness of Internet connectivity. You click on certain links, and afterwards, it takes forever to get to the following page, when you, at last, come to the page, you find that it is not generally that helpful to you. Backing for this statement is given by Hamutoglu\&Basarmak, (2020) which stated that technology factors' 
regarding network were a significant, if not really basic agent for progress. These factors can turn out to be conceivably difficult obstructions for teachers wishing to utilise ICT for their educating and learning exercises.

\section{Lack of training}

Shortage of training has been referred to in writing (Sahboun\&Razak, 2020) as boundaries to powerful utilisation and incorporation of ICT in homeroom setting. Deficient fitting to utilise innovation is one many causes that teachers do not deliberately utilise PCs in their teaching. Proficient advancement is essential for teachers to empower them to adequately utilise and coordinate ICT to improve students' education process. Teachers need preparation for the best way to utilise and coordinate innovation, which should get teachers ready to utilise innovation viably in their classes. The case outcome shows the absence of preparing plans to train teachers on measures to utilise ICT to disentangle their educating and make it simpler for their students to learn better. A few past studies have uncovered that ICT-related preparation programmes build up teachers' skills in a PC application, impact teachers' mentalities towards PCs just as helping teachers rearrange the undertaking of innovation and how new innovative devices are huge in teachingMuslem et al.; 2018; Naveed et al. 2017).

\section{Lack of access}

Past research like Villalba et al 2017; Muslem et al.; 2018; Hamutoglu\&Basarmak, 2020) have referred to the absence of devices as a hindrance to ruining teachers from coordinating ICT into teaching especially into their educating and learning process. The case outcome reveals that the absence of mechanical instruments' absence as an obstruction towards the use and coordination of ICT in teaching and learning. Numerous teachers have no admittance to innovative devices like smart whiteboards and projectors, which can be utilised in the study rooms' visual outlines. The absence of availability to skills and assistance for the utilisation and incorporation of ICT is difficult that is common in numerous class settings in emerging countries. One of the teachers states that "not having enough PCs and absence of availability to the internet that can be an incredible use in scholastic studies and distance learning is a major issue for teachers here in Africa".

As per Makki (2018), availability is one of the fundamental requirements for viable teachers' utilisation of ICT in classroom settings and is significant with respect to viable reconciliation of ICT in educating and learning measure. This is upheld by Sabiri (2020) study which discovered admittance to innovative assets is one of the powerful approaches to teachers' academic utilisation of ICT in teaching. This is predictable with Lawrence, \& Tar (2018) discoveries that availability of ICT tools as the primary snags to the usage of ICT in classrooms. Admittance to ICT framework and devices in institutions is vital to incorporating ICT in teaching. The selection and joining of ICT rely principally upon the convenience and accessibility to ICT devices, for example, physical devices and the programs incorporated inside it. On the off chance that teachers cannot get to ICT devices, at that point, they would not utilise them.

\section{Lack of technical assistance}

The case outcome reveals the absence of specialised help as one of the obstructions brought up about ICT devices being underutilised in the classroom settings, similar to PC in the research facility. One of the teachers proclaimed:

"... few of my colleagues would not like to utilise PCs in their classrooms since they did not know where to go for assistance when something is not right while they are utilising the PCs".

If there is no great specialised help in the classes, teachers would be hesitant to utilise and coordinate ICT into their teaching practices. The case analysis outcome is predictable with past 
research (Sahboun, Razak, 2020) that have referred to the absence of specialised help as hindrances towards utilising and reconciling ICT in teaching and learning measure. Absence of specialised help deters teachers from receiving and incorporating innovation in homerooms as indicated by Hersh\&Mouroutsou (2019) that uncovered the hugeness of specialised help to assist teachers with coordinating innovation into their classrooms. They contended that ICT uphold in institutions' impact teachers to apply ICT in study halls without sitting around idly investigating equipment and programming issues.

\section{Conclusion}

This research focuses on picking up a profound understanding of the elements that impact or concerned teachers' choice to embrace and incorporate ICT in instructing and learning. The research has recognised and discussed the variables that emphatically or adversely impact teachers' utilisation and incorporation in education and learning. The research has built up a selection and inclusion of ICT model that considered the teacherslevel, mechanical and institutional-level variables, that clarified the appropriation and utilisation of ICT in educating and learning. The researcher has contended both hypothetically and conceivably utilising observational proof, why these classes assisted with bettering comprehend and clarifying ICT reception and utilisation in instructing and learning. The research's outcomes offered critical help to assist the discoveries in past related studies. The research was introduced in an engaging structure and narratives the insights and encounters of teachers' utilisation and incorporation in instructing and learning. The research has introduced the current image of the variables that impacted or blocked teachers' choice to embrace and incorporate ICT in instructing and learning. It has recounted the story of ICT incorporation and utilisation from the teachers' viewpoint that partook in the interview sessions.
The finishes of the study depended on the research of the teachers met and not on a populace. It is not the objective of interpretive research to make speculations from the inspected teachers, yet rather to offer arrangement or experiences about the incorporation and utilisation of ICT in educating and learning. A strong, solid account of the case permits peruses to settle on choices concerning the study's adaptability. This research has offered huge advancement in clarifying the components impacting incorporation and utilising ICT in educating and learning. The investigation has added to the current assortment of exploration on innovation use in training when all is said in done and ICT in educating and learning specifically. Lastly, the study proclaimed here adds to what exactly is trusted will be a ceaselessly growing collection of experimental proof that can expand information on ICT appropriation and utilisation in education.

\section{References}

[1] Alakrash, H., Razak, N. A., \&Krish, P. (2020a). Social Network Sites in Learning English; An Investigation on Attitudes, Digital Literacy and Usage. LINGUISTICA ANTVERPIENSIA, 2643.

[2] Razak, N. A., Alakrash, H. M., \&Sahboun, Y. (2018). English Language Teachers' readiness For the Application of Technology Towards Fourth Industrial Revolution Demands. AsiaPacific Journal of Information Technology and Multimedia, 7(2-2), 89-98.

[3] Ageel, M. (2011). The ICT proficiencies of university teachers in Saudi Arabia: A case study to identify challenges and encouragements. Online Submission.

[4] Al Gamdi, M. A., \&Samarji, A. (2016). Perceived barriers towards e-Learning by faculty members at a recently established university in Saudi Arabia. International Journal of Information and Education Technology, 6(1), 23. 
[5] Al Mulhim, E. (2014). The Barriers to the Use of ICT in Teaching in Saudi Arabia: A Review of Literature. Universal Journal of Educational Research, 2(6), 487-493.

[6] Al-Adwan, A., \& Smedley, J. (2012). Implementing e-learning in the Jordanian higher education system: Factors affecting impact. International Journal of Education and Development using Information and Communication Technology, 8(1), 121-135.

[7] Alahmari, A., \&Kyei-Blankson, L. (2016). Adopting and Implementing an E-Learning System for Teaching and Learning in Saudi Public K-12 Schools: The Benefits, Challenges, and Concerns. World Journal of Educational Research, 3(1), 11-32.

[8] Al-Asmari, A. M., \& Khan, M. S. R. (2014). Elearning in Saudi Arabia: Past, present and future. Near and Middle Eastern Journal of Research in Education, 2014(1), 2.

[9] Albugami, S., \& Ahmed, V. (2015). Success factors for ICT implementation in Saudi secondary schools: From the perspective of ICT directors, headteachers, teachers and students. International Journal of Education and Development using ICT, 11(1).

[10] Alakrash, HM, Razak, NA, \& Bustan, ES (2020b). The Effectiveness of Employing Telegram Application in Teaching Vocabulary: A Quasi Experimental Study. Multicultural Education, 6(1).

[11] Algahtani, M. (2017). Factors influencing the adoption of learning management systems in the Kingdom of Saudi Arabian Universities by female academic staff. (Doctoral dissertation), The University of RMIT, Melbourne, Australia.

[12] Alharbi, O., \& Lally, V. (2017). Adoption of elearning in Saudi Arabian University education: Three factors affecting teachers. European Journal of Open Education and E-learning Studies.

[13] Alhawiti, M. M. (2013). Strategies and action plans for integrating ICT into Saudi elementary schools' curricula: The case of Tabuk district of education. International Journal of Information and Education Technology, 3(2), 177.
[14] Alakrash, H., Razak, N, A. (2019). Motivation towards the application of ICT in English language learning among Arab EFL students. Journal of Advanced Research in Dynamical \& Control Systems, 11, 1197-1203.

[15] Alkahtani, A. (2017). The challenges facing the integration of ICT in teaching in Saudi secondary schools. International Journal of Education and Development using ICT, 13(1).

[16] Al-Madani, F. M., \&Allafiajiy, I. A. (2014). Teachers' professional development on ICT use: A Saudi sustainable development model. Journal of Modern Education Review, 4(6), 448-456.

[17] Almaghlouth, O. A. D. (2008). Saudi secondary school science teachers' perceptions of the use of ICT tools to support teaching and learning (Doctoral dissertation, The University of Waikato).

[18] Al-Maini, Y. H. (2013). Issues in Integrating Information Technology in Learning and Teaching EFL: The Saudi Experience. The EUROCALL Review, 21(2), 49-55.

[19] Al-Maliki, S. Q. A. K. (2013). Information and communication technology (ICT) investment in the Kingdom of Saudi Arabia: Assessing strengths and weaknesses. Journal of Organizational Knowledge Management, 2013, 1.

[20] Alakrash, H. M. \& Razak, N. A. (2020a). Redesigning the English Classroom Towards Fourth Industrial Revolution, Are the Students Motivated? The Asian ESP Journal. 6

[21] Almalki, G., \& Williams, N. (2012). A strategy to improve the usage of ICT in the Kingdom of Saudi Arabia primary school. International Journal of Advanced Computer Science \& Application, 3.

[22] Al-Nefaie, S. (2015). Investigating factors influencing students' attitude and performance when using web-enhanced learning in developing countries: The case of Saudi Arabia (Doctoral dissertation, Brunel University London).

[23] Alzahrani, M. G. (2017). The Developments of ICT and the Need for Blended Learning in Saudi 
Arabia. Journal of Education and Practice, 8(9), 79-87.

[24] Alakrash, H. M., \& Razak, N. A. (2020b). Towards the Education 4.0, Readiness Level of EFL

[25] Students in Utilising Technology-Enhanced Classroom. International Journal of Innovation,

[26] Creativity and Change. 13 (10), 161-182.

[27] Asiri, M. J. S. (2012). Factors influencing the use of learning management system in Saudi Arabian higher education: A theoretical framework. Higher Education Studies, 2(2), 125-137.

[28] Hamutoglu, N. B., \&Basarmak, U. (2020). External and Internal Barriers in Technology Integration: A Structural Regression Analysis. Journal of Information Technology Education, 19.

[29] Hersh, M., \&Mouroutsou, S. (2019). Learning technology and disability-Overcoming barriers to inclusion: Evidence from a multicountry study. British Journal of Educational Technology, 50(6), 3329-3344.

[30] Lawrence, J. E., \& Tar, U. A. (2018). Factors that influence teachers' adoption and integration of ICT in teaching/learning process. Educational Media International, 55(1), 79-105.

[31] Makki, T. W., O'Neal, L. J., Cotten, S. R., \&Rikard, R. V. (2018). When first-order barriers are high: A comparison of second-and thirdorder barriers to classroom computing integration. Computers \& Education, 120, 9097.

[32] Muslem, A., Yusuf, Y. Q., \& Juliana, R. (2018). Perceptions and barriers to ICT use among English teachers in Indonesia. Teaching English with Technology, 18(1), 3-23.

[33] Naveed, Q. N., Qureshi, M. R. N., Alsayed, A. O., Muhammad, A., Sanober, S., \& Shah, A. (2017). Prioritizing barriers of E-Learning for effective teaching-learning using fuzzy analytic hierarchy process (FAHP). In 2017 4th IEEE International Conference on Engineering Technologies and Applied Sciences (ICETAS) (pp. 1-8). IEEE.
[34] Oyaid, A. (2009). Education policy in Saudi Arabia and its relation to secondary school teachers' ICT use, perceptions, and views of the future of ICT in education.

[35] Quadri, N. N., Muhammed, A., Sanober, S., Qureshi, M. R. N., \& Shah, A. (2017). Barriers Effecting Successful Implementation of ELearning in Saudi Arabian Universities. International Journal of Emerging Technologies in Learning (iJET), 12(06), 94-107.

[36] Robertson, M., \& Al-Zahrani, A. (2012). Selfefficacy and ICT integration into initial teacher education in Saudi Arabia: Matching policy with practice. Australasian Journal of Educational Technology, 28(7).

[37] Sabiri, K. A. (2020). ICT in EFL teaching and learning: A systematic literature review. Contemporary Educational Technology, 11(2), 177-195.

[38] Sahboun, Y., \& Razak, N. A. (2020). Adoption and Usage of Learning Management System Technologies among EFL Students: Factors and Issues. Solid State Technology, 63(6), 1151911531

[39] Tayan, B. M. (2017). The Saudi Tatweer Education Reforms: Implications of Neoliberal Thought to Saudi Education Policy. International education studies, 10(5), 61-71. 